\title{
Postpartum psychosis
}

\author{
Mesut Işık \\ Van Education and Research Hospital, Department of Psychiatry, V an
}

\begin{abstract}
:
The postpartum period is a risky period for the emergence or exacerbation of psychiatric disorders. Postpartum psychosis is the most severe psychiatric disorder in the postpartum period that requires immediate intervention. In most of the cases, the onset is immediate and it is usually in the first two weeks of postpartum period. Sleep disturbances, mood swings, delusions, hallucinations, disorganized behavior, psychomotor agitation, food rejection may be seen. Due to risk of suicide and infanticide, patients should be admitted to the hospital. The most important treatment option in addition to antipsychotic drug therapy is electroconvulsive therapy. Bipolar disorder or postpartum psychosis history, sleep deprivation, primiparity, postpartum hormone changes are important risk factors. The etiology has not been clearly identified yet, although here are many ongoing studies.
\end{abstract}

Key Words: Postpartum, postpartum psychosis, pregnancy

\section{Definition of Postpartum Psychosis}

Postpartum period is a risky period for psychiatric diseases (1). Women experience 22 times more psychotic or mania episodes in postpartum period than in any other periods of their lives (2). Postpartum Psychosis (PP) is a rare and severe disease. (3). The prevalence of postpartum psychosis has been reported to be $0.1-0.2 \%$ (4).

Postpartum mental disorders are not classified as a separate clinical diagnostic entity in the Diagnostic and Statistical Manual of Mental Disorders-5 (DSM-5) and in the International Classification System of Mental and Behavioral Disorders (ICD) (5). In DSM-5, postpartum psychosis is classified in the "short psychotic disorder" section of the schizophrenia spectrum and other psychotic disorders.

\section{Clinical Manifestation of Postpartum Psychosis}

In most of the cases, the onset is fast and within the first two weeks of postpartum (6). PP has an average onset age of 26 years (7). Early manifestations include symptoms such as insomnia, mood changes, obsessive thoughts about baby, and later delusions, hallucinations, disorganized behavior, psychomotor agitation, food rejection, catatonia, and severe mood changes (8). Unusual psychotic findings are often in the form of reference, persecution, jealousy, grandiose delusions that are incompatible with mood. Delusions often have a bizarre character. "Schneiderian first-line symptoms" are relatively rare (9). Tactile and visual hallucinations that point to the organic syndrome can be seen. Severe mood symptoms such as depression, mania or mixed episodes are frequently observed. Affective phenomenology seems to be a feature of the disorder and is more common in PP than other psychotic disorders (10). Apart from affective symptoms, at the same time bizarre delirium-like symptoms may also be seen. Sometimes atypical cognitive symptoms such as disorientation, confusion can be observed in patients. Due to cognitive disorganization, patients may neglect the newborn and/or dangerous practices may arise while they are meeting the baby's needs (11).

Strange beliefs and thoughts about birth or baby can be seen. In one study, it was stated that 28 $35 \%$ of the women who were admitted with PP diagnosis had delusions about their babies, but only $9 \%$ of them had persecutory thoughts about their baby (12). It has been reported that the risk of suicide increased by 70 times in the first year after birth. Suicide is an important cause of maternal deaths and completed suicide has been reported in 2 of $1000 \mathrm{PP}$ women (13).

Suicidal attempts may be aggressive and irreversible. Although rare, the prevalence of baby killing, which is the most dramatic picture, has been reported to be 4\% (14) and is associated with the denial of the pregnancy. In a study 16 
infanticide cases were examined and it was reported that these mothers were affected by dissociative symptoms (15). These patients denied gravidity and birth pain; usually had dissociative hallucinations, short amnesia and depersonalization. For this reason, caution against suicidal or infanticidal thoughts is warranted and emergency measures and measures to ensure the safety of the patient should be taken.

\section{Risk Factors and Etiology}

Clinical parameters such as primiparity (16,17), puerperal hormone changes (18), sleep deprivation (19), and complications such as increased environmental stress, perinatal death during delivery, congenital malformation (20) have been reported to be risk factors for PP. As a matter of fact, primiparity is always seen as an important variable in modeling risk factors. However, in a study of women who had had first birth without previous psychiatric admission, there was no significant effect of birth complications on PP risk (21).

Bipolar disorder or PP episode history are the most important risk factors for postpartum psychosis. In both cases, the risk of postpartum psychosis in the postpartum period was reported to be $25-50 \%$. (22). The likelihood of developing bipolar disorder after a new onset postpartum affective psychosis is known to be $40-80 \%$ (23). Some studies have reported that $72-88 \%$ of patients with PP develop schizoaffective disorder or bipolar disorder, $12 \%$ of them develop schizophrenia $(24,25)$.

Very little research has been done to determine the association of PP and hormones. After birth, a rapid decline in estrogen and progesterone levels occurs and this is thought to be caused by PP. (26). Estrogen plays a role in dopaminergic activity in the hypothalamus and it has been suggested that there is a relationship between the emergence of affective psychosis after birth and increased sensitivity of dopamine receptors (26). However, this finding was not found in other studies (27). Estrogen receptor or glucocorticoid receptor gene polymorphisms have not been associated with PP $(28,29)$. Postpartum psychosis has been associated with thyroiditis and preeclampsia in studies on the relationship between PP and postnatal immunization (30,31). It has been reported that in $4 \%$ of PP patients, central nervous system autoantibodies have been identified (32) and tryptophan pathway abnormalities have been found (33). It is clear that there is a need for further research to examine the etiology of PP.

\section{Differential Diagnosis of Postpartum Psychosis}

PP is considered an urgent situation which requires a possible hospitalization. A detailed history, physical and neurological examination, laboratory studies, and brain imaging are needed to exclude organic cause of acute psychosis at initial evaluation (34).

The primary psychiatric diagnosis that should be considered in association with early onset PP is bipolar disorder. Elevation, dysphoria, emotional lability, confusion and sleep disturbance are seen in bipolar disorder with psychotic features and PP $(35,9)$. PP patients differ from major depression patients since they have cognitive problems, delusional thinking, disorganized behaviors. Women who had previously psychotic depression may recur by having a PP episode shortly after delivery (36). PP may be the manifestation of a psychotic disorder such as schizophrenia. Despite the fact that previously diagnosed schizophrenia patients carry a risk of $25 \%$ for puerperal exacerbations (11,37), the prevalence of schizophrenia in early-onset PP has been reported to be low in many studies $(3.4 \%-4.5 \%)$ (38).

\section{Prognosis of postpartum psychosis}

Longitudinal studies indicate a good prognosis for women who have experienced PP following bipolar disorder diagnosis. After a single PP episode, $75-86 \%$ of the symptoms are fully recovered (39). Of the patients diagnosed with schizophrenia; 50\% recovered after PP episode, $33 \%$ had recurrent PP episodes and 5\% became treatment resistant after a large number of puerperal and non-puerperal recurrences (40). Women who received help within one month after delivery had favorable outcomes and fewer longterm disability than women with late-onset PP; (13\% and $33 \%$ respectively) (41). PP has been reported to recur in $65 \%$ of long-term follow-up studies (42). In a review of 16 studies, $18-37 \%$ of patients diagnosed with PP had another episode after delivery, whereas $39-81 \%$ reported having an episode without any association with childbirth status (23). In two studies conducted in our country Turkey, 65.2\% (43) and 81.2 (16) cases of PP patients were reported to have recurrent episodes, respectively.

\section{Treatment}

East J Med Volume:23, Number:1, January-March/2018 
PP is an emergency that requires immediate medical intervention and hospital admission. The patient must be hospitalized for maternal care and for the safety of the baby. Small samples, case reports and non-randomized trials were conducted frequently on PP. In the treatment, mood stabilizers, antipsychotics, ECT and benzodiazepines are the first-line drugs of choice. There are no randomized trials for ECT in PP. Positive treatment results were reported with ECT in a series of $5 \mathrm{PP}$ treatment resistant cases (44). In a retrospective study, clinical ECT responses were compared between female patients with PP (58 subjects) and non-postpartum psychosis patients (56 subjects). A greater clinical improvement was seen with ECT in the PP group (45).

As a result, postpartum psychosis is a rare disease, but can seriously affect mother and baby health. The patient should be treated with hospital admission. Detailed history, physical and neurological examination, laboratory evaluations should be done. Investigations are continuing to elucidate the etiology of the disease.

\section{Referances}

1. Konuk N, Öztürk Ü, Karakuș G, Tamam L. Postpartum Obsesif Kompulsif Bozukluk: Bir Gözden Geçirme. Klinik Psikofarmakoloji Bülteni 2007; 17: 142-146.

2. Bergink V, Koorengevel KM. Postpartum depression with psychotic features. Am J Psychiatry 2010; 167: 476-477.

3. Bergink V, Lambregtse-van den Berg MP, Koorengevel KM, Kupka R, Kushner SA. Firstonset psychosis occurring in the postpartum period: a prospective cohort study. J Clin Psychiatry 2011; 72: 1531-1537.

4. Spinelli MG. Postpartum psychosis: detection of risk and management. Am J Psychiatry 2009; 166: 405-408

5. American Psychiatric Association. Diagnostic and statistical manual of mental disorders (4th ed.). Washington, DC: Author, (1994).

6. Heron J, McGuinness M, Blackmore ER, Craddock N, Jones I. Early postpartum symptoms in puerperal psychosis. BJOG 2008; 115: 348-353.

7. Rhode A, Marneros A. Postpartum psychoses: onset and long-term course. Psychopathology 1993; 26: 203-209.

8. Brockington I. Postpartum psychiatric disorders. Lancet 2004; 363: 303-310.

9. Wisner $\mathrm{K}$, Peindl $\mathrm{K}$, Hanusa $\mathrm{BH}$. Symptomatology of affective and psychotic illnesses related to childbearing. J Affect Disord. 1994; 30: 77-87.

10. Brockington IF, Cernik KF, Schofield EM, Downing AR, Francis AF, Keelan C. Puerperal
Psychosis. Phenomena and diagnosis. Arch Gen Psychiatry 1981; 38: 829-833.

11. Seeman MV. Gender differences in the prescribing of antipsychotic drugs. Am J Psychiatry 2004; 161: 1324-1333.

12. Kumar R, Marks M, Platz C, Yoshida K. Clinical survey of a psychiatric mother and baby unit: characteristics of 100 consecutive admissions. J Affect Disord 1995; 33: 11-22.

13. CEMD. Confidential inquiries into maternal deaths: Why mothers die, 1997-99. London: Royal College of Obstetricians and Gynaecologists; 2001.

14. Davidson J, Robertson E. A follow-up study of post partum illness, 1946-1978. Acta Psychiatr Scand 1985; 71: 451-457.

15. Spinelli MG. A systematic investigation of 16 cases of neonaticide. Am J Psychiatry 2001; 158: 811-813.

16. Kirpinar I, Coşkun I, Cayköylü A, Anaç S, Ozer H. First-case postpartum psychoses in Eastern Turkey: a clinical case and follow-up study. Acta Psychiatr Scand 1999; 100: 199-204.

17. Pfuhlmann B, Franzek E, Beckmann H, Stöber G. Long-term course and outcome of severe postpartum psychiatric disorders. Psychopathology 1999; 32: 192-202.

18. Sichel DA, Driscoll JW. Women's moods. New York:William Morrow and Company, Inc 1999

19. Sharma V, Smith A, Khan M. The relationship between duration of labour, time of delivery, and puerperal psychosis. J Affect Disord 2004; 83: 215-220.

20. Makanjuola RO. Psychotic disorders after childbirth in Nigerian women. Trop Geogr Med 1982; 34: 67-72.

21. Valdimarsdottir U, Hultman CM, Harlow B, Cnattingius S, Sparen P. Psychotic illness in firsttime mothers with no previous psychiatric hospitalizations: a population-based study. PLoS Med 2009; 6(2): e13.

22. Noorlander $Y$, Bergink V, van den Berg MP. Perceived and observed mother-child interaction at time of hospitalization and release in postpartum depression and psychosis. Arch Womens Ment Health 2008; 11: 49-56.

23. Chaudron LH, Pies RW. The relationship between postpartum psychosis and bipolar disorder: a review. J Clin Psychiatry 2003; 64: 1284-1292.

24. Brockington IF. Puerperal psychosis: Motherhood and mental health. New York: Oxford University Press 1996: 200.

25. Wisner KL, Peindl KS, Hanusa BH. Psychiatric episodes in women with young children. J Affect Disord 1995; 34: 1-11.

26. Wieck A, Kumar R, Hirst AD, Marks MN, Campbell IC, Checkley SA. Increased sensitivity of dopamine receptors and recurrence of affective psychosis after childbirth BMJ 1991; 303: 613616.

27. Meakin CJ, Brockington IF, Lynch S, Jones SR. Dopamine supersensitivity and hormonal status in 
puerperal psychosis. Br J Psychiatry 1995; 166: 7379.

28. Feng J, Zheng J, Bennett WP, et al. Five missense variants in the amino-terminal domain of the glucocorticoid receptor: no association with puerperal psychosis or schizophrenia. Am J Med Genet 2000; 96: 412-417.

29. Feng J, Yan J, Michaud S, et al. Scanning of estrogen receptor alpha (ERalpha) and thyroid hormone receptor alpha (TRalpha) genes in patients with psychiatric diseases: four missense mutations identified in ERalpha gene. Am J Med Genet 2001; 105:369-374.

30. Bergink V, Kushner SA, Pop V, et al. Prevalence of autoimmune thyroid dysfunction in postpartum psychosis. Br J Psychiatry 2011; 198: 264-268.

31. Bergink V, Laursen TM, Johannsen BM, Kushner SA, Meltzer-Brody S, Munk-Olsen T. Preeclampsia and first-onset postpartum psychiatric episodes: a Danish populationbased cohort study. Psychol Med 2015; 45: 3481-3489.

32. Bergink V, Armangue T, Titulaer MJ, Markx S, Dalmau J, Kushner SA. Autoimmune encephalitis in postpartum psychosis. Am J Psychiatry 2015; 172: 901-908

33. Veen C, Myint AM, Burgerhout KM et al. Tryptophan pathway alterations in the postpartum period and in acute postpartum psychosis and depression. J Affect Disord 2016; 189: 298-305.

34. Sit D, Rothschild AJ, Wisner KL. A review of postpartum psychosis. J Womens Health (Larchmt) 2006; 15: 352-368.

35. Dilsaver SC, Chen YR, Shoaib AM, Swann AC. Phenomenology of mania: evidence for distinct depressed, dysphoric, and euphoric presentations. Am J Psychiatry 1999; 156: 426-430.

36. Agrawal P, Bhatia MS, Malik SC. Postpartum psychosis: a study of indoor cases in a general hospital psychiatric clinic. Acta Psychiatr Scand 1990; 81: 571-575.

37. Bosanac P, Buist A, Burrows G. Motherhood and schizophrenic illnesses: a review of the literature. Aust N Z J Psychiatry 2003; 37: 24-30.

38. Kumar R. Postnatal mental illness: a transcultural perspective. Soc Psychiatry Psychiatr Epidemiol 1994; 29: 250-264.

39. Jabs BE, Pfuhlmann B, Bartsch AJ, CetkovichBakmas MG, Stöber GJ. Cycloid psychoses- from clinical concepts to biological foundations. Neural Transm 2002; 109: 907-919.

40. Protheroe C. Puerperal psychoses: a long term study 1927-1961. Br J Psychiatry 1969; 115: 9-30.

41. Pfuhlmann B, Stoeber $G$, Beckmann $H$. Postpartum psychoses: prognosis, risk factors, and treatment. Curr Psychiatry Rep 2002 J; 4: 185190.

42. Müller C. On the nosology of post-partum psychoses. Psychopathology 1985; 18: 181-184.

43. Kısa C, Aydemir Ç, Kurt A, Gülen S, Göka E. Doğum Ardı Psikoz Tanısı Konulan Hastaların Uzun Süreli İzlemi. Türk Psikiyatri Dergisi 2007; 18: 223-230.

44. Forray A, Ostroff RB. The use of electroconvulsive therapy in postpartum affective disorders. J ECT 2007; 23: 188-193.

45. Reed P, Sermin N, Appleby L, Faragher B. A comparison of clinical response to electroconvulsive therapy in puerperal and nonpuerperal psychoses. J Affect Disord 1999; 54: 255-260. 